\title{
The Arabidopsis synaptonemal complex protein ZYP1 is required for chromosome synapsis and normal fidelity of crossing over
}

\author{
James D. Higgins, ${ }^{1}$ Eugenio Sanchez-Moran, ${ }^{1}$ Susan J. Armstrong, Gareth H. Jones, and \\ F. Chris. H. Franklin ${ }^{2}$ \\ School of Biosciences, The University of Birmingham, Birmingham B15 2TT, United Kingdom
}

\begin{abstract}
The duplicated Arabidopsis genes ZYP1a/ZYP1b encode closely related proteins with structural similarity to the synaptonemal complex (SC) transverse filament proteins from other species. Immunolocalization detects ZYP1 foci at late leptotene, which lengthen until at pachytene fluorescent signals extending the entire length of the fully synapsed homologs are observed. Analysis of zyp1a and zyp1b T-DNA insertion mutants indicates that the proteins are functionally redundant. The SC is not formed in the absence of ZYP1 and prophase I progression is significantly delayed suggesting the existence of an intraprophase I surveillance mechanism. Recombination is only slightly reduced in the absence of ZYP1 such that the chiasma frequency at metaphase I is $\sim \mathbf{8 0} \%$ of wild type. Moreover cytological analysis indicates that chiasma distribution within zyp1 bivalents is indistinguishable from wild type, providing evidence that the SC is not required for the imposition of interference. Importantly in the absence of ZYP1, recombination occurs between both homologous and nonhomologous chromosomes suggesting the protein is required to ensure the fidelity of meiotic chromosome associations.
\end{abstract}

[Keywords: Meiosis; synaptonemal complex; recombination; Arabidopsis]

Supplemental material is available at http://www.genesdev.org.

Received June 7, 2005; revised version accepted August 2, 2005.

The pairing and synapsis of homologous chromosomes during prophase I of meiosis are essential for their subsequent orderly segregation during anaphase of the first meiotic division. During this process each homologous chromosome pair becomes intimately associated (synapsed) by a cytologically prominent ultrastructural feature, the synaptonemal complex (SC). Establishment of the SC follows an initial alignment and loose pairing of the homologous chromosomes that occurs in early prophase I. Initially a linear protein axis, the axial element (AE), forms in association with the paired sister chromatids of each chromosome. As prophase I progresses from leptotene through zygotene, the homologous chromosomes are increasingly juxtaposed into a close alignment, such that the AEs lie within $\sim 400 \mathrm{~nm}$ of each other. This initial pairing leads to homolog synapsis that is characterized by the appearance of transverse fila-

\footnotetext{
${ }^{1}$ These authors contributed equally to this work.

${ }^{2}$ Corresponding author.

E-MAIL f.c.h.franklin@bham.ac.uk; FAX 44-121-41-45925.

Article and publication are at http://www.genesdev.org/cgi/doi/10.1101/ gad.354705.
}

ments (TFs) that span the gap between the chromosome axes, now referred to as lateral elements. The zone where the TFs meet and interdigitate constitutes the central element that runs parallel to and between the lateral elements. This process is completed by pachytene, at which time the homologous chromosomes are completely synapsed and linked by a fully formed tripartite SC along their length. As meiosis progresses through diplotene/diakinesis the SC disassembles, so that the homologous chromosomes remain associated only by chiasmata, the cytologically visible structures that correspond to sites of reciprocal crossovers (COs) (for review, see Heyting 1996; Zickler and Kleckner 1999).

Despite the high degree of ultrastructural similarity between SCs from a wide variety of eukaryotic organisms, the degree of conservation at the primary sequence level of the protein components that comprise the SC is remarkably limited. This is exemplified by the TF proteins Zip1, SYP1, C $(3) \mathrm{G}$, and SCP1 from budding yeast, Caenorhabditis elegans, Drosophila, and mammals, respectively (Meuwissen et al. 1992; Sym et al. 1993; Heyting 1996; Zickler and Kleckner 1999; Page and Hawley 2001; MacQueen et al. 2002; Vazquez et al. 2002). None of these proteins exhibit significant homology at the 
amino acid level, yet they share similar structural properties that account for conservation of SC ultrastructure. These proteins possess a central domain that is mainly comprised of coiled-coil, flanked at the $\mathrm{N}$ and $\mathrm{C}$ termini by globular domains (Heyting 1996; Page and Hawley 2004). Studies of Zipl in yeast and SCP1 in mouse indi- cate that the TFs form parallel homodimers that are oriented such that their $\mathrm{C}$ termini align along the lateral elements. The $\mathrm{N}$ termini of opposed dimers overlap in the central region of the $\mathrm{SC}$, giving rise to the central element (Fig. 1A).

Evidence from a variety of sources points to a complex
A

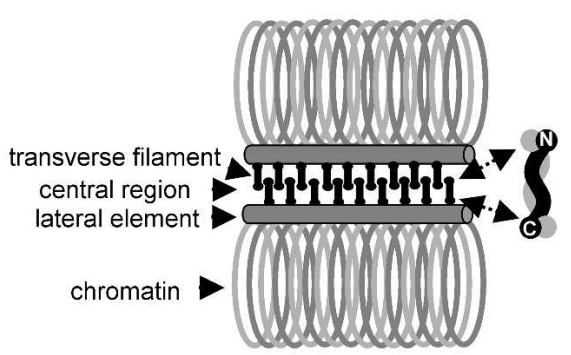

B

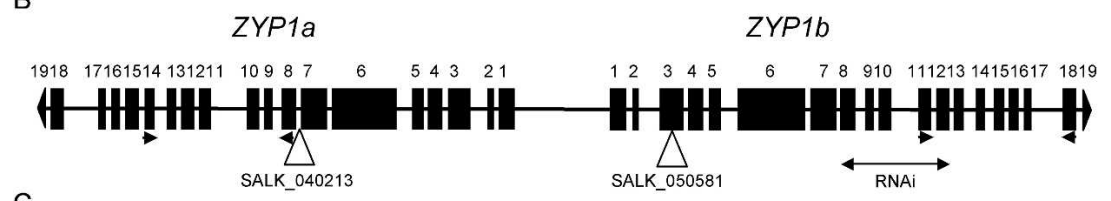

ZYP 1 (a

ZYP1

MOKLGEPAMKSIDKPRSLSGSANMYSESNRKPPDSVSSGSFSNLKLTAEKLVKDOAAMRTDLELANCKLKKSMEHVYALE 80

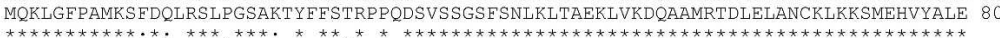

ZYP1a

EKLQNAFNENAKLRVRKKEDEKLWRGLESKFSSTKTLCDQLTETLQHLASQVQDAEKDKGEFETKFSTSSEAIDSLNQQM 160 EKLQSAFNENAKLRVRQKEDERLWRGLESKFSSTKTLCDQLTETLQHLASQVQDAEKDKGFFETKENTSSEAINSLNQQM 160

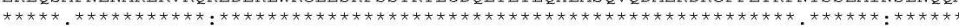

ZYP1

ZYP1D

RDMSLRLDAAKEEITSRDKELEELKLLERQQKEMFYQTERCGTASLIEKKDAVITKLEASAAERKLNIENLNSQLERVHLE 240 RDDSLRLDAAREEITSRDKELEELKLEKQHKEMF YQTERCGTASLIEKKDAVITELETTTAAERKLKIEKLNSQLEKLHLE 240

ZYP1a

ITTKEDEVKDLVSTQEKLEKERTSVQLSADNCEEKLVSSEQEVKKIDELVQYUVAELTELDKKNLTFKEKFDKLSGLYDT 320 LTTKEDEVIHLVSIQEKLEKEKTNVQLSSDELEEKLVRSEQEVKRLDELVHYLIAELTELDKKNLTEKEKFDKLSGLYDT 320

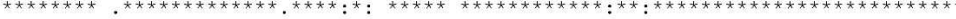

ZYP1 ZYP1

HIMLLOKDRDLALDRAORSFDNLOGELFRVAATKEALESAGNELNEKIVEIONDKESLISOLSGLRCSTSOTIDKLESEA 400 HFMLLRKDRDLASDRAQRSFDQLQGELERVAAEKFALESSGNELSEKTVEIQNDKESLISQLSGVRCSASQT IDKLEFEA 400

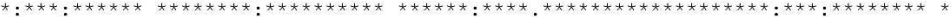

ZYP1a KGLVSKHADAESAISQLKEEMETLIESVKTSEDKKQELSLKLSSLEMESKEKCEKLQADAQRQVEELETLQKESESHQIQ 480 ZYP1b KGLVLKNAETESVISRLKEEIDTLLESVRTSEDKKKELSIKLSSLEIESKDKYEKLQADAORQVGEIETLQRESESHOLQ 480

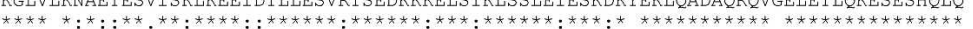

ZYP1a ADLLAKEVNQLQTVIEEKGHVILQCNENEKQLNQQI IKDKEILATAETKLAEAKKQYDLMLESKQLEISRHLKELISQRND 560

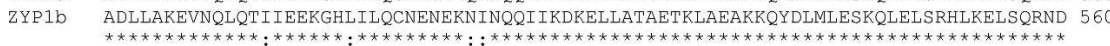

ZYPT

ZYP1b

QAINEIRRKYDVEKHEI INSERDKVEKI IKDLSNNKFDKELSDCREESKRQLITIQEEHSSL ILSLREEHESKELNLKAKY 640 QAINEIRRKYDVEKHEI INSEKDKVEKIIKELSTKYDKGLSDCKEESKRQILTI QEEHSSRILNIREEHESKELNLKAKY 640

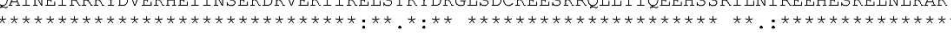

ZYP1a DQELRQSQI QAENELKERITALKSEHDAQLKAEKCQYEDDCKKLQEELDDLRRKEERQRALVQLQWKVMSDNPPEEQEVN 720 ZYP1b DQELRQNQI QAENELKERITALKSEHDAQLKAERCQYEDDCKKLQEELDLQRKKEERQRALVQLQWKYMSDNPPEEQEVN 720

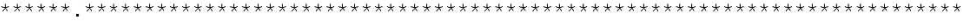

ZYP1a SNKNYSIS----KDSRLGGSKRSEHIRVRSDNDNVQDSPFVKAKETPVSKILKKAQNVNAGSVLSI PNPKHHSKVTHREY 794 ZYPIb -NPKHHSKVTHREY 780

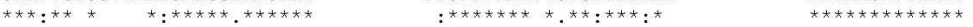

ZYP1a FVETNNGRVTKRRKTRNTTMFEEPORRRTRATPKL-TPQSIAKGTGMTSHARSANIGDLFSEGSLNPYADDPYAFD ZYP1b EVETNNGRIPKRRKTRQTTMEQEPQRRSTRLTPKLMTPTI IAKETAMADHPHSANIGDLFSEGSLNPYADDPYAFD

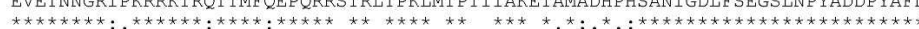

D

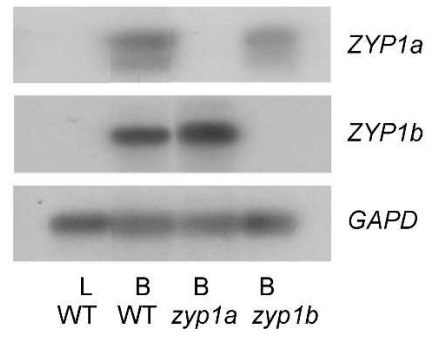

Figure 1. SC structure: organization of the ZYP1 locus, protein alignment, and gene expression analysis. (A) Diagram of the SC structure showing the organization of the TFs, which form parallel homodimers with their $\mathrm{C}$ termini associated with the lateral elements and the $\mathrm{N}$ termini of opposing dimers overlapping in the central region of the SC. (B) The 13-kb $Z Y P 1$ locus showing the orientations of $Z Y P 1 a$ and ZYP1b. Exons are represented by black boxes and the triangles show locations of the SALK T-DNA insertions. The arrows below the exons represent the positions of the gene-specific primers used for expression analysis, and the doubleheaded arrow shows the region of the cDNA used for the RNAi construct. $(C) \mathrm{A}$ ClustalW alignment of ZYP1a and ZYP1b protein sequences. (D) RT-PCR expression analysis of ZYP1a and ZYP1b with wildtype (WT) leaf (L) and bud (B), and Salk_040213 (zyp1a) and Salk_050581 $(z y p 1 b)$ bud (B) tissue performed with genespecific primers. The housekeeping gene GAPD is the control for ZYP1 expression. 
interrelationship between the SC and meiotic recombination. Studies in yeast, mouse and Arabidopsis have revealed that SC formation is dependent upon recombination initiation and processing of early recombination intermediates. (Baudat et al. 2000; Romanienko and Camerini-Otero 2000; Grelon et al. 2001; Mahadevaiah et al. 2001). It has been proposed that in a broad range of organisms close juxtaposition of homolog axes and formation of SC between them are mediated by axial associations arising from early recombination events (Albini and Jones 1987; Rockmill et al. 1995; Tesse et al. 2003). In contrast, C. elegans and Drosophila possess cis-acting pairing regions that promote local pairing stabilization (MacQueen et al. 2002).

The SC has been extensively investigated in plants, but identification and cloning of genes encoding plant SC proteins has proved elusive. While a number of asynaptic and desynaptic mutants have been identified in a variety of plant species, including Arabidopsis, so far this has not led to the identification of genes encoding SC proteins. In all the Arabidopsis mutants analyzed to date, the synaptic phenotype has arisen as a consequence of a primary failure in sister chromatid cohesion, homolog pairing or recombination (Jones et al. 2003).

A recent in silico study has sought to overcome the problem of lack of primary sequence homology for identification of SC proteins (Bogdanov et al. 2003). Using the example of the TF proteins, database searching based upon conserved secondary structure was used to identify potential homologs in different species. In this study we applied a similar in silico strategy in order to identify a candidate for the Arabidopsis TF protein. This led to the identification of two virtually identical genes designated ZYP1a and ZYP1b located adjacent to each other on chromosome 1. Subsequent analysis of Arabidopsis lines that are deficient in the two corresponding proteins, coupled with immunolocalization studies indicates that they localize to the central region of the SC and are required for normal chromosome synapsis during prophase I of meiosis. Our data provide the first characterization of a plant SC gene and provide new insights into the function of the SC and its relationship with meiotic recombination.

\section{Results}

Identification of ZYP1a and ZYP1b

The TF proteins previously characterized in mammals (Meuwissen et al. 1992, 1997), yeast (Sym et al. 1993), Drosophila (Page and Hawley 2001), and C. elegans (MacQueen et al. 2002) were used in a BLAST search against the Arabidopsis proteome. This gave a list of 220 proteins that were ranked according to the BLAST scores. The structural constraints acting on the TF proteins give a mean amino acid number of 866 , a mass of $100 \mathrm{KDa}$ and an isoelectric point (pI) of 6. The proteins have an extended coiled-coil flanked by globular domains at the $\mathrm{N}$ and $\mathrm{C}$ termini. The $\mathrm{C}$-terminal domain has a very high pI (10) and contains putative DNA-bind- ing repeats S/TPXX (Suzuki 1989). Two of the proteins, ranked 30 and 40 in the BLAST search, were found to possess these properties.

Genes At1g22260 and At1g22275 designated ZYP1a and $Z Y P 1 b$ respectively are encoded on opposite strands of a 13-kb region on chromosome 1 (Fig. 1B). The start codons are separated by $2 \mathrm{~kb}$ and transcribed in opposite directions. cDNA clones of each gene were obtained using RT-PCR combined with $5^{\prime}$ - and $3^{\prime}$-RACE-PCR. ZYP1a encodes a 2920-base-pair (bp) mRNA transcript of which $2616 \mathrm{bp}$ is coding region and $Z Y P 1 b$ produces a 2874-bp transcript with a 2571-bp coding region. At the nucleotide level the genes share 93\% homology. ZYP1a encodes a protein of 871 amino acid residues and $Z Y P 1 b$ 856 residues (Fig. 1C). The N-terminal globular domains are basic with 55 residues that share $83 \%$ similarity. The central coiled-coil regions both comprise 650 residues and share $95 \%$ similarity. The C-globular domains of ZYP1a and ZYP1b are 166 and 151 residues, respectively, and share $75 \%$ similarity. RT-PCR expression analysis revealed that both genes are expressed in meiotic flower buds, but not in leaf tissue (Fig. 1D).

\section{ZYP1a and ZYP1b localization}

The distribution and chronology of ZYP1a and ZYP1b proteins, referred to collectively as ZYP1, was investigated by fluorescence immunolocalization on DAPIstained spread preparations of anthers from young flower buds using a polyclonal antibody raised against a recombinant protein comprising amino acids residues 422-845 of ZYP1b. Our assumption that the antibody would recognize both ZYP1a and ZYP1b was confirmed by immunolocalization studies in T-DNA insertion lines lacking either ZYP1a or ZYP1b (see later). The results reveal that ZYP1 is restricted to meiocytes at prophase I of meiosis. Twenty to 25 fluorescent ZYP1 foci per nucleus $(n=50)$ first became visible at leptotene. During zygotene the individual foci extended and coalesced to form linear signals such that by pachytene single fluorescent signals extended the entire lengths of the five fully synapsed homologs (Fig. 2A-D). This interpretation assumes that the leptotene foci are the sites of SC nucleation. In isolation these observations are insufficient evidence to draw such conclusion, but the behavior of ZYP1 in a $d m c 1$ mutant (see below) suggests that this is probably the case.

To define the spatial and temporal distribution of ZYP1 more precisely dual immunolocalization studies were carried out using anti-ZYP1 Ab in conjunction with anti-ASY1 Ab. ASY1 is an axis-associated protein that is required for synapsis and a normal level of recombination (Armstrong et al. 2002). ASY1 is first detectable at late G2/early leptotene as discrete foci and precedes the appearance of ZYP1. By the time ZYP1 foci appear ASY1 has developed to form more continuous signals along the unsynapsed chromosome axes. As synapsis progresses both proteins are found along the prophase I bivalents with the ZYP1 signal becoming progressively more continuous. At pachytene both proteins form linear signals 

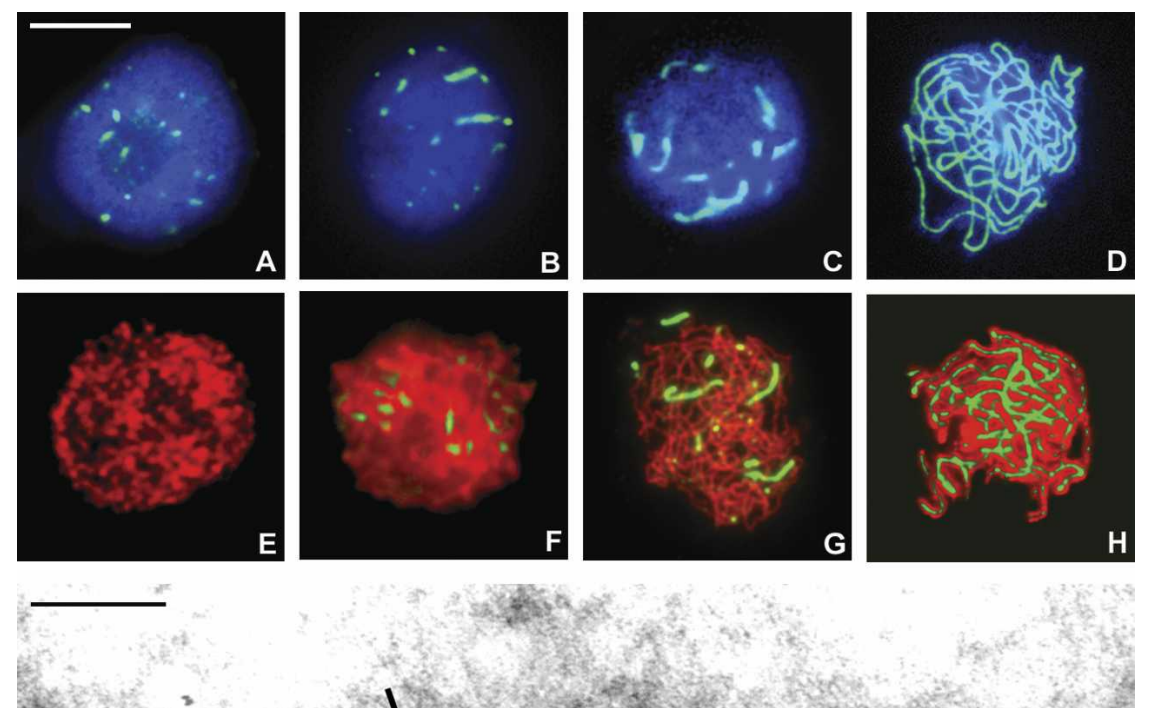

\section{H} $(D)$ of wild type. Counterstained with DAPI (blue). Bar, $10 \mu \mathrm{m}$. $(E-H)$ Dual immunolocalization of ZYP1 protein (green) and ASY1 protein (red) to early leptotene $(E)$, early zygotene $(F)$, mid-zygotene $(G)$, and pachytene $(H)$ showing that ZYP1 protein appears after ASY1 loading and the localization of ZYP1 protein between axisassociated ASY1. Bar, $10 \mu \mathrm{m}$. (I) Immunogold localization of anti-ZYP1 Ab. The distribution and spacing of the gold particles (arrows) is consistent with localization to the inner surface of the lateral elements. Bar, $100 \mathrm{~nm}$. along each bivalent. The ZYP1 signal is flanked on either side by the axis-associated ASY1 signal, consistent with ZYP1 forming a component of the SC (Fig. 2E-H).

Ultrastructural localization using immunogold labelled anti-ZYP1 Ab confirmed that ZYP1 localizes to the SC (Fig. 2I). The spacing and distribution of the gold particles indicates that they align along the inner surface of the lateral elements consistent with the $\mathrm{Ab}$ having been raised against the C-terminal region of ZYP1.

\section{ZYP1 localization requires initiation of recombination}

To determine if the appearance of axis-associated ZYP1 foci is dependent on initiation and progression of recombination, immunolocalization of ZYP1 was performed in two mutants defective in the recombination pathway. The SPO11 protein catalyzes the formation of meiotic DNA double-strand breaks (DSBs), and hence the Arabidopsis spo11 mutant is unable to form DSBs and fails to make COs (Grelon et al. 2001). ZYP1 localization did not occur in this mutant, but instead the protein was found in the cytoplasm surrounding the chromatin (Fig. 3A) indicating that the correct localization of ZYP1 is dependent on DSB formation.

The DMC1 protein forms a complex with its homologous partner RAD51 to catalyze strand invasion of homologous chromosomes by free 3' DNA strands that arise from the $5{ }^{\prime}-3^{\prime}$ directed resection of DSBs (Bishop et al. 1992; Bishop 1994). Hence dmc1 mutants are proficient in DSB formation, but are blocked thereafter at an early stage in the recombination pathway. Dual-immunolocalization using anti-ZYP1 Ab and anti-ASY1 Ab on early prophase I chromosome spread preparations from the Arabidopsis dmc1 mutant (Klimyuk and Jones 1997) revealed ZYP1 foci localized to or closely associated with the unsynapsed chromosome axes (Fig. 3B). As far as could be discerned the ZYP1 foci were associated with sites where the chromosome axes converge or lie in close proximity. In a few cases the foci appeared to have elongated very slightly. Overall this distribution was indistinguishable from that observed in wild-type meiocytes at early prophase I but, in contrast to wild type, the ZYP1 foci failed to develop to form extended linear signals. Thus it appears that initial localization of ZYP1 is dependent upon DSB formation and occurs when recombination is at an early stage, prior to extensive strand invasion. However, subsequent ZYP1 polymerization to bring about homologous chromosome synapsis cannot occur if recombination is blocked at an early step.

\section{Identical distribution of ZYP1a and ZYP1b}

To investigate the function of ZYP1a and ZYP1b and to resolve whether they are functionally redundant, two SALK T-DNA insertion lines SALK_040213 (zyp1a) and SALK_050581 (zyp1b) were identified. The insertion site within locus ZYP1a was mapped to position 7862830 in intron 7 and that of $Z Y P 1 b$ to position 7867882 in exon 3. RT-PCR analysis using gene specific primers revealed no evidence of residual transcripts suggesting that in 

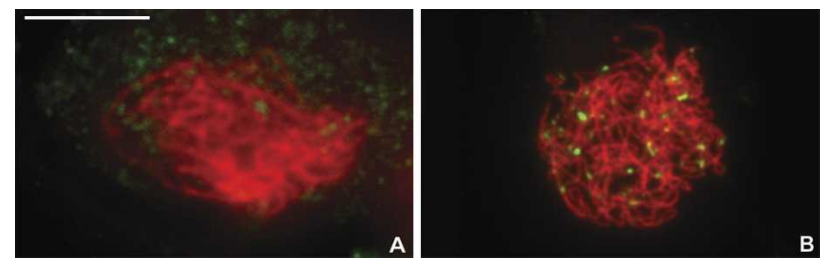

Figure 3. Dual immunolocalization of ASY1 (red) and ZYP1 (green) to prophase I nuclei of spo11 $(A)$ and $d m c 1(B)$ mutants. ZYP1 foci are localized to chromosome axes in $d m c 1(B)$ but not in spo11 $(A)$ where the protein is present but not localized to the chromosomes. Bar, $10 \mu \mathrm{m}$.

both instances the T-DNA insertion had resulted in a null mutation (Fig. 1D). Both lines showed normal vegetative growth and development but exhibited a reduction in fertility, indicative of a possible meiotic defect. The mean seed set per silique for zyp $1 a$ was 30.2 and for zyp $1 b 33.2$, an overall reduction of $\sim 30 \%-40 \%$ compared with the $\mathrm{Col}(0)$ accession. This indicated that both proteins are required for wild-type levels of fertility. Immunolocalization studies using the anti-ZYP1 Ab were carried out on prophase I stage meiocytes isolated from the mutant lines. Since RT-PCR analysis indicated that the T-DNA insertion in both zyp $1 a$ and zyp $1 b$ had resulted in a null-mutation it was presumed that the residual ZYP1 protein in the former was ZYP1b and in the latter ZYP1a. In both cases an identical spatial and temporal distribution of ZYP1 protein was observed and this appeared to be the same as in wild type (cf. Figs. 4A-D and 2C,D). Thus, the pattern of localization, combined with their identical mutant phenotypes suggest that ZYP1a and ZYP1b are functionally redundant and that the loss of one protein through mutation can be compensated to a significant degree by the remaining protein.

Depletion of ZYP1 results in a delay in progression through meiotic prophase I

Despite chromosome synapsis appearing complete in both mutants, they exhibited a $\sim 40 \%$ reduction in seed set. A cytological survey of zyp $1 a$ and zyp $1 b$ revealed no major differences from wild type aside from a small reduction in mean chiasma frequency from the wild-type level of 9.86 to 8.95 in zyp1a and to 9.05 in zyp1b. Mutations in SC TF components in other organisms show delayed progression through prophase I, specifically due to a block at the leptotene/zygotene transition. The zyp1 mutants exhibited a disproportionately low number of late zygotene/pachytene meiocytes, consistent with this possibility. To assess prophase I progression directly meiotic time courses were determined for the mutant lines using pulse-chase labelling of nuclear DNA in meiotic S phase followed by sampling and assessment of meiotic progress by anti-BrdU Ab detection in chromosome spread preparations (Armstrong et al. 2003). In wild-type plants the duration of meiosis from the end of $\mathrm{S}$ phase to the tetrad stage is $\sim 33 \mathrm{~h}$. The majority of this is occupied by prophase I, which takes some $30 \mathrm{~h}$. In both zyp $1 a$ and zyp $1 b$ progress through prophase I was delayed by $\sim 6 \mathrm{~h}$ (Fig. 5A).

RNA interference confirms chromosome synapsis is dependent on ZYP1

The analysis of the T-DNA insertion lines suggested that ZYP1a and ZYP1b are functionally redundant and hence to investigate their role more fully we constructed lines lacking both proteins simultaneously. Despite the availability of the T-DNA insertion mutants, using them to generate a T-DNA double knockout of ZYP1a and ZYP1b was not feasible because it would require a CO event in the $2-\mathrm{kb}$ region that separates the start codons of the two genes. An RNA interference (RNAi) construct was made based on a 476-bp cDNA fragment of the ZYP1b gene, which shared $97 \%$ nucleotide identity with the paralogous region in ZYP1a (Fig. 1B). To maximize efficiency, the RNAi construct was placed under control of the meiosis specific DMC1 promoter and used to transform homozygous zyp $1 a$ and zyp $1 b$ plants as these were already depleted for either ZYP1a or ZYP1b and therefore potentially more susceptible to RNAi knock-
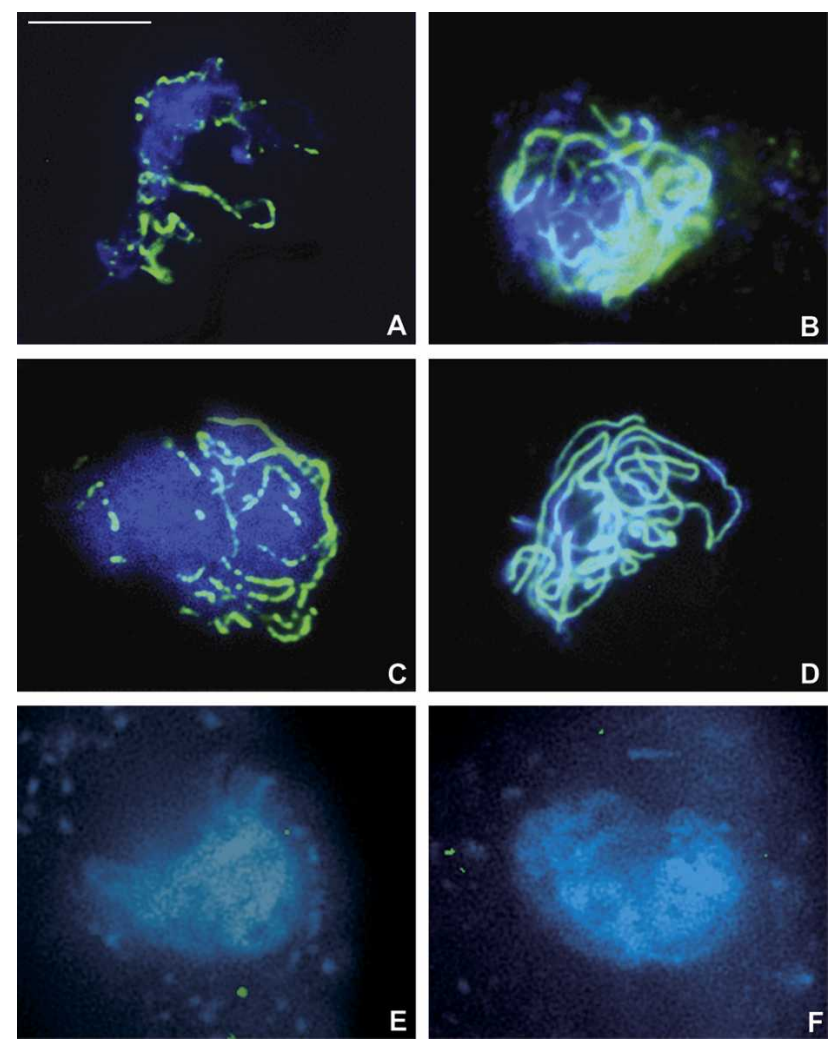

Figure 4. Immunolocalization of ZYP1 protein to zygotene $(A, C)$ and pachytene $(B, D)$ of T-DNA mutants zyp $1 a(A, B)$ and zyp $1 b(C, D)$ showing that the patterns of ZYP1 localization are identical in the two mutants. Counterstained with DAPI (blue). Immunolocalization of ZYP1 protein to prophase nuclei of $Z Y P 1^{\text {RNAi1 }}(E)$ and $Z Y P 1^{\text {RNAi4 }}(F)$ plants showing no detectable ZYP1 protein. Counterstained with DAPI (blue). Bar, $10 \mu \mathrm{m}$. 

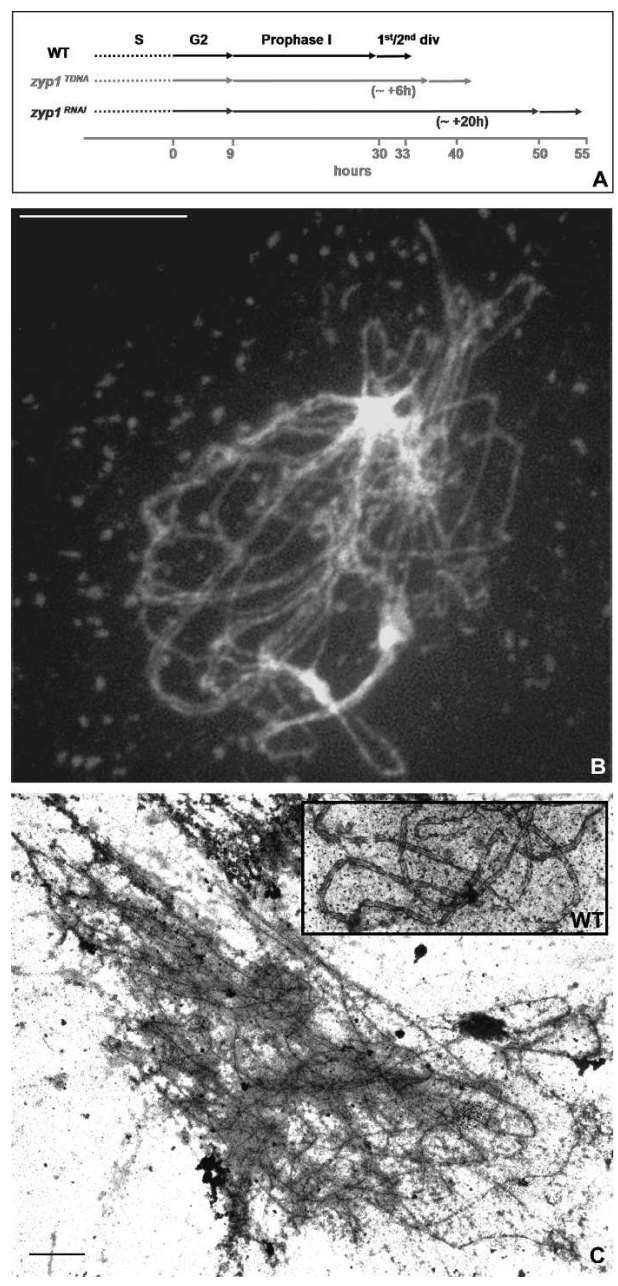

Figure 5. (A) Meiotic time courses for wild-type, zyp1 T-DNA mutant, and $Z Y P 1^{R N A i}$ plants. Light $(B)$ and electron $(C)$ micrographs showing axis alignment but absence of synapsis in $Z Y P 1^{R N A i}$ plant(s). Inset shows normal tripartite $\mathrm{SC}$ in wild type. Bars: $B, 10 \mu \mathrm{m} ; C, 2 \mu \mathrm{m}$.

down of the remaining ZYP1 protein. Sixty transformants were obtained in the zyp1a background and 80 in zyp $1 b$. These displayed a range of effects on fertility from plants with short $(<5 \mathrm{~mm})$ siliques to plants with normal $(\sim 12 \mathrm{~mm})$ silique lengths. Three transformed lines from each background $\left(Z Y P^{R N A i 1-3}\right.$ in zyp $1 a$ and $Z Y P^{R N A i 4-6}$ in zyp $1 b$ ) exhibiting short siliques and with a mean seed set per silique ranging from 0.5 to 6.2 were selected for further analysis.

To determine if RNAi had resulted in a substantial or complete knockdown of ZYP1 expression, immunolocalization studies were conducted using anti-ZYP1 Ab on chromosome spreads from meiocytes at prophase I. In contrast to the wild-type and T-DNA insertion lines, the ZYP1 protein could not be detected in the meiocytes from the $Z Y P^{R N A i 1-6}$ lines suggesting that expression of the protein had been abolished (Fig. 4E,F). Similarly RTPCR analysis failed to detect residual ZYP1 RNA transcripts (data not shown).
Prophase I progression is delayed in the absence of ZYP1

Cytological examination of $Z Y P^{R N A i 1-6}$ chromosome spreads revealed that $\mathrm{AE}$ development in early prophase was normal, but the majority of prophase I nuclei showed little or no chromosome alignment. However a small proportion of nuclei $(<1 \%)$ showed extensive alignment that was evident at the LM and EM levels (Fig. $5 \mathrm{~B}, \mathrm{C})$; fully synapsed pachytene stage nuclei were not seen. In these nuclei the chromosomes were arranged in parallel alignment over long distances, resembling presynaptic alignment, suggesting that all the interactions that hold presynaptically aligned chromosome axes together are still present at this stage. This resembles the situation in the corresponding mouse mutant (de Vries et al. 2005), but not what is seen in yeast where alignment or association of axes occurs only in specific sites corresponding to $\mathrm{CO}$ sites, alternating with regions of axis separation (Sym et al. 1993). The huge preponderance of nuclei lacking chromosome alignment indicates a greatly extended duration of this early prophase I stage, suggesting a problem in meiotic progression.

This was confirmed by a BrdU time course showing that progress through prophase I was severely delayed in $Z Y P^{R N A i 1}$ such that the first meiotic division did not occur until $\sim 50 \mathrm{~h}$ after meiotic $\mathrm{S}$ phase. This represents a delay of $\sim 20 \mathrm{~h}$ compared with wild type and some $14 \mathrm{~h}$ longer than observed in the zyp $1 a$ and zyp1b T-DNA mutants (Fig. 5A).

\section{Loss of ZYP1 results in aberrant associations and recombination between nonhomologous chromosomes}

Synaptic failure and delay in progression through prophase I are likely symptomatic of a defect or defects in meiotic recombination. To investigate this possibility we conducted immunological and cytogenetical assays of CO-correlated structures that are detectable in later stages of meiosis. Immunolocalization studies were conducted using an antibody that recognizes the MutL homolog MLH1 that is known to be present at and to mark CO sites (Marcon and Moens 2003). Although the exact function of this protein and the related MLH3 have not been fully resolved it is clear that they are crucial at later stages of the meiotic recombination pathway with a role in the resolution of double Holliday junctions to promote CO formation (Roeder 1997). Fluorescent foci corresponding to MLH1 were detected in association with the axes in chromosome spreads of late prophase I nuclei from $Z Y P^{R N A i 1}$ (Fig. 6A,B; Supplementary Fig. 1). The average number of foci per nucleus was lower than wildtype nuclei. In the case of $Z Y P^{R N A i 1}$ a mean of 7.3 (range, 6-9) MLH1 foci $(n=22)$ was recorded compared with 10 in wild type $(n=32)$. We have previously noted that meiotic mutants blocked at an early stage in the recombination pathway display aberrant MLH1 localization, accumulating in the nucleolus (Sanchez-Moran et al. 2004). Thus, the reduction in the number of foci aside, the apparently normal localization of MLH1 suggested that 
Higgins et al.

Figure 6. (A) Dual immunolocalization of ZYP1 protein (green) and MLH1 protein (red) to wild type showing localization of MLH1 foci to synapsed chromosomes. $(B)$ MLH1 foci on unsynapsed chromosomes of $Z Y P 1^{R N A i}$. Chromosomes are counterstained with DAPI (blue). $(C-G)$ FISH of metaphase I nuclei to show examples of chromosome associations. (C) Five bivalents in a wild-type nucleus. (D) Three homologous bivalents, one nonhomologous bivalent $(1,5)$, and two univalents. (E) Two bivalents and an association of six chromosomes $(2,2,4,4,5,5)$. (F) Three bivalents and an association of four chromosomes $(2,2,5,5)$ showing interstitial (solid arrow) and distal (open arrow) nonhomologous chiasmata. (G) A complicated association of all 10 chromosomes. (H) An anaphase I nucleus from a T2 plant showing transfer, by crossing over, of a chromosome 1 distal triple BAC (green) to chromosome 4, marked by the 5 srRNA probe (boxed). The crossover event detected must have occurred in the $\mathrm{T} 1$ generation. This plant also has 11 chromosomes resulting from meiotic nondisjunction of chromosome 5 in the $\mathrm{T} 1$ generation. Bars, $10 \mu \mathrm{m}$.
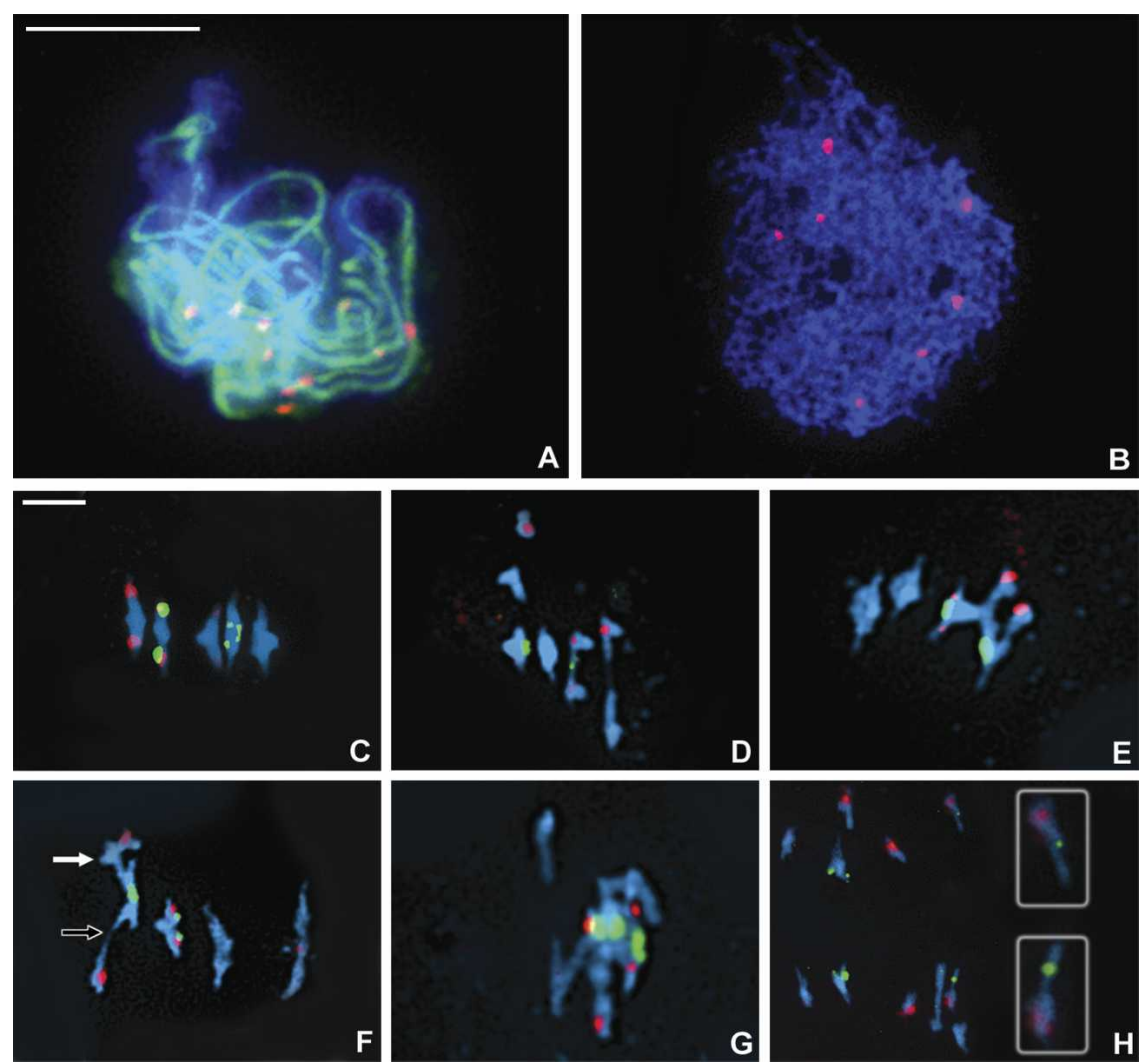

loss of ZYP1 protein did not prevent progress to the later stages of recombination.

The later meiotic phenotypes of $Z Y P^{R N A i 1-6}$ plants were analyzed with the original intention of determining the effect(s) of ZYP1 depletion on chiasma formation. FISH using the $45 \mathrm{~S}$ and $5 \mathrm{~S}$ rDNA probes was applied to the preparations for individual chromosome recognition as previously described (Sanchez-Moran et al. 2002). A striking feature of the $Z Y P^{R N A i 1-6}$ plants analyzed in this way was the presence of multiple chromosome associations (multivalents) in meiocytes that had progressed to late prophase I and metaphase I. These multivalents ranged in size from associations of three chromosomes to the extreme case of all ten chromosomes being associated. In addition bivalents and some univalents were also present in many cells (Fig. 6C-G).

Two different first generation (T1) transformants $Z Y P^{R N A i 1}$ and $Z Y P^{R N A i 4}$, were analyzed, with the RNAi construct inserted in zyp1a or in zyp $1 b$ respectively. In addition meiosis was analyzed in second generation (T2) descendants of these initial transformants. The data are summarized in Table 1 and presented in full in Supplementary Tables 1-4. The association patterns of chromosomes at metaphase I were strikingly similar in all four $Z Y P^{R N A i}$ plants analyzed, independently of generation (T1 or T2) and of the genetic background (zyp1a or zyp1b). Most cells had either one or two multivalent associations each, ranging in size from three to 10 chromosomes, but averaging between 4.41 and 5.29 chromosomes per multivalent in different plants. Similarly the mean numbers of bivalent associations and univalents were also rather similar in the different plants. In most cases bivalent associations involved homologous pairs of chromosomes, but in a few instances two nonhomologous chromosomes were associated as bivalents. Overall the ratio of homologous to nonhomologous associations was 2.63:1 (384 associations in 59 cells).

The FISH analysis clearly shows that the multivalent associations involve various combinations of homologous and nonhomologous chromosome associations (Fig. 6C-G). Since the homologous bivalents can be clearly seen to be maintained by chiasmatic associations, as in wild type, there is a sound basis for inferring that the homologous associations within multivalents are also chiasmatic, and indeed in many instances this can be clearly observed (Fig. 6E). Direct observation of metaphase I multivalents and nonhomologous bivalents indicate that nonhomologous associations are also chiasmatic. In many cases there is clear evidence of typical cross-shaped structures diagnostic of interstitial chiasmata (Fig. 6F). To confirm the existence of nonhomologous chiasmata we sought evidence for recombination between nonhomologous chromosomes in post-metaphase I stages. For this purpose, the $5 \mathrm{~S}$ rDNA FISH probe that marks chromosomes 3, 4, and 5 was combined with a triple-BAC probe (three contiguous BACs) that marks the subterminal region of chromosome 1. Anaphase I and metaphase II stages were then screened for evidence of nonhomologous recombination between chromosome 1 and any of the other three marked chromosomes. Al- 
Table 1. Mean numbers of multivalents, bivalents and univalents, multivalent sizes, and chiasma frequencies for selected T1 and T2 ZYP RNAi plants

\begin{tabular}{lcccc}
\hline Plants & $Z Y P^{R N A i 1}(\mathrm{~T} 1)$ & $Z Y P^{R N A i 1}(\mathrm{~T} 2)$ & $Z Y P^{R N A i 4}(\mathrm{~T} 1)$ & $Z Y P^{R N A 4}(\mathrm{~T} 2)$ \\
\hline Multivalents & $1.13(1-2)$ & $0.89(0-1)$ & $1.27(0-2)$ & $0.79(0-2)$ \\
Bivalents & $2.00(1-3)$ & $2.11(1-3)$ & $1.27(0-3)$ & $2.50(0-5)$ \\
Univalents & $1.20(1-4)$ & $2.00(1-4)$ & $0.91(0-2)$ & $1.21(0-4)$ \\
Multivalent size & $4.41(3-7)$ & $4.75(3-6)$ & $5.29(3-10)$ & $4.79(3-8)$ \\
Chiasmata & $7.40(5-9)$ & $7.00(5-9)$ & $9.10(7-10)$ & $6.96(4-10)$ \\
Number of cells & 15 & & 11 & 24 \\
\hline
\end{tabular}

though such cases were infrequent, clear and unequivocal examples of such recombination events were observed (Fig. 6H), thus confirming that COs leading to chiasmata do occur between nonhomologs in the absence of ZYP1.

Estimating the mean chiasma frequencies of the $Z Y P^{R N A i}$ plants presented some problems due to the difficulty, in some cases, of fully interpreting complex multivalent structures. To overcome this we resorted, in problem cases, to assuming the minimum numbers of chiasmata that would be required to maintain the multivalent associations. On this basis the chiasma scores could be somewhat underestimated. However, this could be counterbalanced by the fact that some multivalents may include chromosomes held in by persistent, unresolved, interlocks (see Discussion) that are not chiasmadependent. The estimated mean chiasma frequencies of the four $Z Y P^{R N A i}$ plants range between 6.96 and 8.10 per cell. Although these values are somewhat lower than wild type (9.86) they are still reasonably high, indicating that the ZYP1 protein is not an absolute requirement for crossing over and chiasma formation. Nevertheless the chiasma frequencies of these plants are clearly depressed relative to wild type. This is additionally confirmed by the occurrence of between 1 and 4 univalents in most cells, that could reflect an overall reduction in CO frequency or loss of the ability to specify the first (obligatory) CO.

\section{Discussion}

Since its discovery in 1956 the SC has been extensively characterized at the cytological level in a wide range of species including many plants (Zickler and Kleckner 1999). The SC is found in the majority of eukaryotes and is ultrastructurally conserved. Genes encoding SC components have been identified in a number of organisms; however, ZYP1 is the first SC gene to be identified and characterized from a plant. Moreover functional analysis of ZYP1 has provided new insights into SC function that has not previously been reported in any organism.

\section{ZYP1a and ZYP1b: a duplicated gene that encodes a component of the Arabidopsis SC with similarity to the TF proteins from other eukaryotes}

Chromosome synapsis commences at the onset of zygotene and is complete at pachytene. During this period the TF protein polymerizes along the closely juxtaposed homologous chromosomes to form the central region of the SC that links the lateral elements of the homologs. Evidence presented in this study provides strong evidence that ZYP1a and ZYP1b form the TFs of the Arabidopsis SC.

Proteins encoding the TF of the SC identified in budding yeast, mammals, Drosophila and C. elegans exhibit extensive structural similarities. However these are not reflected at the primary amino acid sequence level, hence the identification of the corresponding proteins in different species is not straightforward. To overcome this limitation, Bogdanov et al. (2003) applied an in silico approach based on the analysis of conserved protein domains coupled with physico-chemical properties of the proteins. They proposed the Arabidopsis protein AAD10695 as a TF candidate, although no functional evidence was presented to confirm this. In this study, we adopted a similar approach, but initiated the screen by conducting a BLAST search of the Arabidopsis proteome. By this means we identified proteins ZYP1a and ZYP1b as primary candidates, but protein AAD10695 was not ranked in our analysis. It also contains a structural domain that exhibits significant homology to a guanylate-binding protein $\left(E=4 \mathrm{e}^{-81}\right)$, a feature that is not found in other TFs. The limited primary sequence homology between TF proteins is emphasized in the comparison of the Arabidopsis ZYP1 proteins with Zip1 from budding yeast, SCP1 from mammals and C/3)G from Drosophila, with which they share $18 \%-20 \%$ sequence identity and $36 \%-40 \%$ similarity.

The localization of ZYP1 protein during leptotene/zygotene is dependent on SPO11 catalyzed DSB formation. This seems different to budding yeast where recent studies indicate that some Zip1 protein associates with the centromeres in the absence of DSBs (Tsubouchi and Roeder 2005) suggesting that this centromeric interaction is important in homolog pairing. However previous studies indicate that homolog pairing in Arabidopsis is telomere-led (Armstrong et al. 2001), and centromeres play no active part in this process.

Localization of the ZYP1 protein to the the SC is indicated by dual-immunolabeling with anti-ASY Ab and immunogold labeling. Confirmation that ZYP1 is integral to SC formation was obtained using RNAi interference to simultaneously knock-down expression of $Z Y P 1 a$ and ZYP1b. As far as we can deduce using both immunolocalization with anti-ZYP1 Ab and RT-PCR, 
expression of both proteins is abolished in the lines selected for analysis. As a result plants fail to establish tripartite SC and have dramatically reduced fertility. Together these observations provide compelling evidence that ZYP1a and ZYP1b encode the Arabidopsis TF and as such represent the first SC gene(s) to be isolated from a higher plant.

\section{ZYP1a and ZYP1b are functionally indistinguishable}

Several lines of evidence suggest that ZYP1a and ZYP1b share identical or largely overlapping functions. First, the two genes that encode them are $93 \%$ identical at the nucleotide level and are located in reverse tandem orientation on chromosome 1. It seems likely that they arose from a gene duplication event following the divergence of the Arabidopsis and Brassica genera 12-19 million years ago (Arabidopsis Genome Initiative 2000). This is based on the observation that Brassica oleracea possesses a single ZYP1 gene and the fact that the two Arabidopsis homologs are more closely related to each other than either is to their Brassica counterpart (J.D. Higgins, unpubl.). Second, immunolocalization studies have established that their temporal and spatial distribution is, as far we can discern, identical. Third, T-DNA insertion lines zyp $1 a$ and zyp $1 b$ display identical phenotypes. Both mutants exhibit a reduction in chiasma frequency, producing on average about one fewer chiasma per nucleus than the wild type. Although our analysis indicates that full synapsis is achieved in both mutant lines, this is delayed by $\sim 6 \mathrm{~h}$ compared with wild type. A reduction in fertility of some $40 \%$ is also observed in both cases.

When RNAi was used to knockdown ZYP1a expression in the zyp1b line and ZYP1b in zyp1a, the effect was identical. These two classes of knockdown dramatically reduced fertility, were indistinguishable at a cytological level, and had a delay of $\sim 20 \mathrm{~h}$ in progression through prophase I. Thus, while it is conceivable that subtle differences in function do exist and may emerge following further analysis, current data strongly suggest that ZYP1a and ZYP1b are functionally redundant.

\section{Delayed progression through meiotic prophase I}

Recent studies in budding yeast of the ZMM complex, which comprises Zip1/2/3, Msh4/5, and Mer3, have led to the proposal of a surveillance mechanism that monitors progression through prophase I (Borner et al. 2004). Analysis of individual $\mathrm{zmm}$ mutants at high temperature $\left(33^{\circ} \mathrm{C}\right)$ has revealed a defect preventing the progression of CO-designated DSBs to the single-end invasion stage. Importantly, this prophase arrest is the result of a block in recombination and not SC formation, suggesting the existence of a recombination checkpoint at late leptotene. In $z \mathrm{~mm}$ mutants grown at low temperature $\left(23^{\circ} \mathrm{C}\right)$, recombination and prophase I progression is efficient, but subject to a long delay. Under these conditions it is suggested that CO-designated DSBs are initially unable to progress, but in contrast to high-temperature conditions, they eventually do so. However, it appears that a proportion of them lose their $\mathrm{CO}$ designation and instead mature as non-COs (Borner et al. 2004). It is suggested that the differential responses of $z \mathrm{~mm}$ mutants to different conditions are a consequence of the surveillance mechanism sensing underlying problems with chromosomal processes and then ensuring the correct regulatory response. A delay in prophase I progression or prophase I arrest dependent on the conditions under which meiosis is functioning is also observed in some mouse meiotic mutants (Hunt and Hassold 2002). In this case female meiosis continues, albeit with an increase in aneuploidy, whereas the corresponding mutation in male results in prophase I arrest.

The ZYP1-deficient lines analyzed in this study progress through prophase I to form COs, but in all cases progress through prophase is delayed. In the case of the T-DNA mutants there is a modest delay of $6 \mathrm{~h}$, whereas in $Z Y P^{R N A i 1}$ a substantial delay of $\sim 20 \mathrm{~h}$ is observed that appears to be due to an extension of early prophase I. This behavior is remarkably similar to that of the budding yeast $\mathrm{zmm}$ mutants at low temperature. Hence it seems likely that as in budding yeast, Arabidopsis has an intraprophase I surveillance mechanism that monitors problems in the progression of recombination.

\section{Recombination occurs in the absence of ZYP1 proteins}

Despite a delay in prophase progression our studies have revealed that loss of ZYP1 reduces, but does not prevent recombination. The $Z Y P^{R N A i}$ plants have a mean chiasma frequency of $7-8$, some $70 \%-80 \%$ of the normal wild-type level. This corresponds closely to the number of MLH1 foci that are detectable in late prophase I nuclei using immunocytochemistry. Using the number of MLH1 foci to infer the number of CO interactions does assume that in the absence of ZYP1 their turnover remains normal and that there is no delay that could lead to an overestimation of recombination events. However, the close correspondence between the number of MLH1 foci and chiasmata suggests that the estimate of $\mathrm{CO}$ interactions based on MLH1 foci is valid.

The chiasmata that are formed appear entirely normal in appearance and the chromosomes segregate cleanly at anaphase I, forming few if any sticky bridges. This suggests that double Holliday junctions are resolved as normal. It has been proposed that the yeast Zip1 protein has a recombination function that is separable from its role in chromosome synapsis that might involve a few molecules of Zip1 at the CO site (Storlazzi et al. 1996). In this study, we have down-regulated ZYP1 expression using RNAi. Molecular analysis of the lines selected for study revealed no evidence for any residual ZYP1 expression. Thus, it would appear that ZYP1 is not essential for recombination per se, but loss of the protein does directly or indirectly affect the overall level of recombination. 


\section{Crossover interference in the absence of ZYP1}

Initial analysis of Saccharomyces cerevisiae zip1 mutants led to the conclusion that SC assembly is required for the establishment of interference (Sym et al. 1993). However, recent studies have questioned the role of Zip1 and hence SC polymerization in the mediation of interference. Zip1 localization and subsequent polymerization has been shown to be dependent on the prior, independent formation of Zip2/3 foci, which form a synaptic initiation complex (SIC). The Zip2/3 foci are found at designated CO sites and, significantly, their distribution in a zip1 background displays interference (Fung et al. 2004). Moreover, analysis of single and double mutants in genes encoding components of the ZMM complex have revealed that the $\mathrm{CO} /$ nonCO decision is made in early prophase I prior to stable strand exchange and is not dependent on SC formation (Borner et al. 2004). Together, these data argue against a role for Zip1 in mediating crossover interference. Similarly studies of Drosophila lines expressing mutant alleles of the TF protein C(3)G that result in abnormal SC formation reveal that $\mathrm{CO}$ interference is only marginally reduced (Page and Hawley 2001). Based on our analysis, it seems that ZYP1 is unlikely to have a role in interference. Reduction in the level of ZYP1 protein by T-DNA insertion of either $Z Y P 1 a$ or ZYP1b clearly has a detrimental effect on the rate of SC assembly, yet the number of COs per bivalent and their distribution appears normal. In the $Z Y P^{R N A i}$ lines where ZYP1 is absent, most cells contain multivalents in which the distribution of the chiasmata is difficult to assess. Nevertheless, most cells also contain from one to three bivalents (see Supplemental Material). In a sample of 60 bivalents from 24 cells $\left(Z \mathrm{YP}^{\mathrm{RNA} 4}\right)^{\text {, the }}$ number of chiasmata per bivalent is within the range of one to three, which is identical to that seen in wild type. Moreover, in 49 bivalents having two chiasmata, these are nearly always (46/49) in opposite chromosome arms, as in wild type. Although the level of interference in this material has not been assessed by rigorous genetic testing, these cytological observations strongly suggest that $\mathrm{CO}$ interference is maintained in the absence of ZYP1 protein. The observed distribution of chiasmata between bivalent arms is consistent with the operation of interference across the centromere, as detected in other species (Jones 1984).

The SC is essential for fidelity of meiotic recombination

The most notable feature of the cytological analysis of the $Z Y P^{R N A i}$ lines was the detection of extensive multivalent formation involving both homologous and nonhomologous chromosomes. In some cells the complexity of the multivalent associations was such that the possibility that these associations contained interlocked chromosomes could not be discounted. It has been argued that budding yeast Zip1 protein is not required for interlock resolution (Sym et al. 1993). However, it should be noted that the chromosomes of $S$. cerevisiae are small (range, 0.23-1.5 Mb) and it is reported that interlockings are rare in species with short chromosomes compared with organisms with larger chromosomes (Zickler and Kleckner 1999|. The size range of the Arabidopsis chromosomes is $17.5-29 \mathrm{Mb}$, and hence interlocks may well occur. In this regard it is interesting to note that ZYP1a and ZYP1b contain a domain with similarity to the bacterial DNA topoisomerase IV (ParC; residues 180-491), a subfamily of the type IIA topisomerases. It has been proposed that topoisomerase II activity may have a role in interlock resolution (von Wettstein et al. 1984). A rice ZYP1 homolog (CAE75876) also contains this domain (residues 597-714), but nothing similar is found in the yeast Zip1 protein (NCBI-CDD).

Regardless of whether some of the multivalents contain interlocked chromosomes it is quite clear that in the absence of ZYP1 and thus homolog synapsis, both homologous and nonhomologous recombination occurs. Such nonhomologous associations are not found in wildtype Arabidopsis. Recombination between nonhomologous chromosomes has not been reported in SC mutants from other species including yeast. Hence, it could reflect a diverged function for ZYP1 compared with TFs from other organisms. However an important feature of the Arabidopsis genome is that it contains extensive duplications amounting to an estimated $58 \%$ of the genome, suggesting that it may have arisen from a tetraploid ancestor. Polyploidy is widespread among plants and is proposed to have had an important role in the evolution of $70 \%-80 \%$ of plant species (Moore and Purugganan 2005). The existence of extensive regions of duplicated DNA creates particular problems for accurate pairing and synapsis during meiosis. Plants have evolved mechanisms to deal with this, such as the extensively studied Ph1 gene in hexaploid wheat, which is required to prevent associations between homeologous chromosomes (Martinez-Perez et al. 2003). Recently the maize PHS1 gene has been described that has a role in chromosome homology recognition (Pawlowski et al. 2004). Mutation of this gene results in extensive (95\%) nonhomologous synapsis. Significantly, maize is also believed to have undergone genome duplication during its evolution. Although PHS1 is not thought to be an SC component, it is interesting to note that despite lack of overall homology with ZYP1, a database search reveals the presence of a bacterial DNA topoisomerase IV domain within the protein, albeit a different region to that in ZYP1.

It is clear that nonhomologous recombination is an important consequence of ZYP1 loss. Nevertheless, the underlying reason for it remains to be resolved. One explanation is that nonhomologous associations normally occur but are removed by formation of the SC or by some other meiotic process that is dependent on SC formation. One such possibility is the reorganization of the chromosomes into the synizetic knot that occurs concurrently with SC assembly in Arabidopsis (Ross et al. 1996). Alternatively, it is possible that the recombination defect in the ZYP1-deficient lines destabilizes the normal homologous interactions at leptotene/zygotene, 
Higgins et al.

such that a proportion forms new aberrant associations elsewhere.

\section{Materials and methods}

\section{Plant material and nucleic acid extraction}

Arabidopsis thaliana ecotype Columbia (0) [Col (0)] was used in this study for wild-type analysis. The T-DNA insertion lines SALK_040213 and SALK_050581 were obtained from the SALK Institute via NASC for mutant analysis. Plants were grown, material was harvested, and nucleic acid extractions were performed as previously described by Higgins et al. (2004).

\section{Cloning the full-length ZYP1a and ZYP1b cDNAs}

Superscript II $\mathrm{RNase}^{-}$reverse transcriptase (Invitrogen) was used with an Oligo-dT(16) primer to synthesize cDNA from 10 $\mu \mathrm{g}$ Col (0) total bud RNA. The cDNA was subject to PCR using REDTAQ (ABgene) with gene specific primers F1 (5'-ATGCA GAAGTTAGGGTTTCCG-3') and R1 (5'-CAATCAAATGCAT AGGGATCATC-3') designed to amplify the predicted coding regions of At1g22260 (ZYP1a) and At1g22275 (ZYP1b). The PCR products were cloned into pCR2.1 (Invitrogen) and sequenced. This sequence was used to design specific primers for RACE PCR. 3'RACE was carried out using the 17AP [5'GACTCGAGTCGACATCGA $\left.(T)_{17^{-}} 3^{\prime}\right]$ and ZYP1a3'RACE $\left(5^{\prime}\right.$ GGAAGCGTACTGAGCATTCC-3') and ZYP1b3'RACE (5'CACATTCGTCGGTCAAAGTG-3') and $3^{\prime}$ RACE nested (5'GGGAGCCACAAAGACGCAG-3') primer for both genes. The 5'RACE was carried out as follows: cDNA was synthesized from $20 \mu \mathrm{g}$ of total bud RNA using Superscript II RNase ${ }^{-}$reverse transcriptase with the 5'RACE primer 5'-CATCCTGAACTT GAGAAGCC-3'. The cDNA was tailed with dCTP using Terminal Transferase (Roche). Nested PCR was then performed with the following gene specific primers: ZYP1a5'RACE $\left(5^{\prime}\right.$ CTGATCCTTCACCAGTT-3') and ZYP1b5'RACE nested (5'TGCTGCAGAGTCTCAGTAAG- $3^{\prime}$ ), together with the $5^{\prime}$ RACE Abridged Anchor primer (5'-GGCCACGCGTCGACTAGTAC GGGIIGGGIIGGGIIG-3') (Invitrogen). The PCR products were cloned into pDrive (Qiagen) and sequenced.

\section{Semi-quantitative RT-PCR for transcript expression}

RT-PCR was carried out as previously described (Higgins et al. 2004). The gene specific primers for ZYP1a were $5^{\prime}$-GAGCTAC TGGCAACTGCTGA-3' and 5'-CCTCACTCTTATATGCTCG C-3' and for ZYP1b were 5'-GGATTCTCAATATTCGGGAG$3^{\prime}$ and R1 (see above).

\section{T-DNA insertion site mapping}

The T-DNA insertion site of SALK_040213 was mapped with primers LBal (5'-TGGTTCACGTAGTGGGCCATCG-3') and ZYP1aT-DNAR1 (5'-ATGCTGATGCAGAATCAGCG-3'). The T-DNA insertion site of SALK_050581 was mapped with LBa1 and F1 primers. The PCR products were cloned into pDrive (Qiagen) and sequenced. Pairs of primers were used to determine if the plants were homozygous or heterozygous for the T-DNA insertion. Primers F1 and ZYP1aR2 (5'-TACCTGGTCGTT CCTCTGTG-3') were used to amplify the wild-type genomic region of SALK_040213 and primers F1 and ZYP1bR2 (5' -CAT CCTGAACTTGAGAAGCC-3') for SALK_050581.

\section{Construction of ZYP1b RNA interference cassette}

A 476-bp fragment of ZYP1b (between 1583 and 2059 bp relative to the ATG+1) was amplified from Arabidopsis bud cDNA with the following primer pairs: 5'-GGAATTCTTTCAACTGAGC ATCATGCTC-3' (EcoRI)/5'-GCTCGAGAAGCAAA-GAAGCA ATATGACCTG-3' (XhoI) and 5'-GAAGCTTTCAACTGAG CATCATGCTCACTC-3' (HindIII)/5'-AGGATCCAGAAGCAA AGAAGCAATATGACCTG-3' (BamHI). The PCR fragments were cloned into pDrive (Qiagen) and sequenced. An EcoRI/ Xhol digest produced a sense fragment when ligated into the same sites of pHannibal (Wesley et al. 2001) and a HindIII/ BamHI digest produced an antisense insert when ligated into pHannibal. A XhoI/SpeI digest gave a $2.7-\mathrm{kb}$ fragment containing the sense-intron-antisense $Z Y P 1 b$ sequences and the OCS terminator, which was ligated into the same sites of pPF408, downstream of the Arabidopsis DMC1 promoter (Klimyuk and Jones 1997).

\section{Plant transformation}

The binary plasmid pPF408 containing the ZYP1b RNAi construct was introduced into Agrobacterium tumefaciens (LBA4404) and plants were transformed as previously described (Higgins et al. 2004). To select transformants, cotyledons were sprayed with glufosinate-ammonium $(0.25 \mathrm{~g} / \mathrm{L})$. Plants were then sprayed twice more at $8-10-d$ intervals. PCR was performed on the selected plants for presence of the pHannibal intron with primers pHanF $\left(5^{\prime}\right.$-TCCCAACTGTAATCAATCC$\left.3^{\prime}\right)$ and pHanR (5'-GACAAGTGATGTGTAAGACG-3').

\section{Antibody production}

A 1272-bp fragment of ZYP1b (amino acids 422-845) was amplified from Arabidopsis bud cDNA. An NdeI site was designed into primer ZYP1bF (5'-CGCATATGTGGATACTTTATTGG AAAGTG-3') and a NotI site into primer ZYP1bR (5'-TAGCG GCCGCGGGGAACCTTCTGAAAAC-3'). The PCR fragment was digested with NdeI/NotI and ligated into the expression vector pET21b (Novagen). The construct was transferred to Escherichia coli BL21 cells (Novagen) and purified refolded recombinant protein was prepared as described previously (Kakeda et al. 1998). Rabbit and rat polyclonal antisera were produced against the recombinant protein (ISL).

\section{Nucleic acid sequencing}

Nucleotide sequencing was carried out by the genomics laboratory, Biosciences, The University of Birmingham.

\section{Cytological procedures}

The cytological methods were carried out as previously described (Higgins et al. 2004) using the following antibodies: antiZYP1 (rabbit/rat), anti-ASY1 (rabbit) and anti-AtMLH1 (rabbit). FISH with BACs F19K16, F9E10, and F5I6 (chromosome 1), and the $5 S$ rDNA probe was used to identify recombination of heterologous chromosomes.

\section{Acknowledgments}

We are grateful to Stephen Price, the horticulture staff, and the genomics and EM units for technical support. We thank Dr. Marie-Pascale Doutriaux for the DMC1 promoter clone. We particularly thank the anonymous reviewer for comments that enabled a significant improvement to the final version of the 
manuscript. The work was funded by the Biotechnology and Biological Science Research Council, UK.

\section{References}

Albini, S.M. and Jones, G.H. 1987. Synaptonemal complex spreading in Allium cepa and Allium fistulosum I. The initiation and sequence of pairing. Chromosoma 95: 324-338.

Arabidopsis Genome Initiative. 2000. Analysis of the genome sequence of the flowering plant Arabidopsis thaliana. $\mathrm{Na}$ ture 408: 796-815.

Armstrong, S.J., Franklin, F.C.H., and Jones, G.H. 2001. Nucleolus-associated telomere clustering and pairing precede meiotic chromosome synapsis in Arabidopsis thaliana. J. Cell Sci. 114: 4207-4217.

Armstrong, S.J., Caryl, A.P., Jones, G.H., and Franklin, F.C.H. 2002. Asyl, a protein required for melotic chromosome synapsis, localizes to axis-associated chromatin in Arabidopsis and Brassica. J. Cell Sci. 115: 3645-3655.

Armstrong, S.J., Franklin, F.C.H., and Jones, G.H. 2003. A meiotic time-course for Arabidopsis thaliana. Sex. Plant Reprod. 16: 141-149.

Baudat, F., Manova, K., Yuen, J.P., Jasin, M., and Keeney, S. 2000. Chromosome synapsis defects and sexually dimorphic meiotic progression in mice lacking Spo11. Mol. Cell 6: 989998.

Bishop, D.K. 1994. Reca homologs Dmc1 and Rad51 interact to form multiple nuclear-complexes prior to meiotic chromosome synapsis. Cell 79: 1081-1092.

Bishop, D.K., Park, D., Xu, L.Z., and Kleckner, N. 1992. Dmc1 a meiosis-specific yeast homolog of Escherichia coli reca required for recombination, synaptonemal complex-formation, and cell-cycle progression. Cell 69: 439-456.

Bogdanov, Y., Dadashev, S., and Grishaeva, T. 2003. In silico search for functionally similar proteins involved in meiosis and recombination in evolutionary distant organisms. In Silico Biol. 3: 173-185.

Borner, G.V., Kleckner, N., and Hunter, N. 2004. Crossover/ noncrossover differentiation, synaptonemal complex formation, and regulatory surveillance at the leptotene/zygotene transition of meiosis. Cell 117: 29-45.

de Vries, F.A.T., de Boer, E., van den Bosch, M., Baarends, W.M., Ooms, M., Yuan, L., Liu, J.-G., van Zeeland, A.A., Heyting, C., and Pastink, A. 2005. Mouse Sycp1 functions in synaptonemal complex assembly, meiotic recombination, and XY body formation. Genes \& Dev. 19: 1376-1389.

Fung, J.C., Rockmill, B., Odell, M., and Roeder, G.S. 2004. Imposition of crossover interference through the nonrandom distribution of synapsis initiation complexes. Cell 116: 795802.

Grelon, M., Vezon, D., Gendrot, G., and Pelletier, G. 2001. AtSPO11-1 is necessary for efficient meiotic recombination in plants. $E M B O$ I. 20: 589-600.

Heyting, C. 1996. Synaptonemal complexes: Structure and function. Curr. Opin. Cell Biol. 8: 389-396.

Higgins, J.D., Armstrong, S.J., Franklin, F.C.H., and Jones, G.H. 2004. The Arabidopsis MutS homolog AtMSH4 functions at an early step in recombination: Evidence for two classes of recombination in Arabidopsis. Genes \& Dev. 18: 25572570.

Hunt, P.A. and Hassold, T.J. 2002. Sex matters in meiosis. Science 296: 2181-2183.

Jones, G.H. 1984. The control of chiasma distribution. SEB Symp. 38: 293-320.

Jones, G.H., Armstrong, S.J., Caryl, A.P., and Franklin, F.C.H.
2003. Meiotic chromosome synapsis and recombination in Arabidopsis thaliana; an integration of cytological and molecular approaches. Chromosome Res. 11: 205-215.

Kakeda, K., Jordan, N.D., Conner, A., Ride, J.P., Franklin-Tong, V.E., and Franklin, F.C.H. 1998. Identification of residues in a hydrophilic loop of the Papaver rhoeas S protein that play a crucial role in recognition of incompatible pollen. Plant Cell 10: 1723-1731.

Klimyuk, V.I. and Jones, J.D.G. 1997. AtDMC1, the Arabidopsis homologue of the yeast DMC1 gene: Characterization, transposon-induced allelic variation and meiosis-associated expression. Plant J. 11: 1-14.

MacQueen, A.J., Colaiacovo, M.P., McDonald, K., and Villeneuve, A.M. 2002. Synapsis-dependent and -independent mechanisms stabilize homolog pairing during meiotic prophase in C. elegans. Genes \& Dev. 16: 2428-2442.

Mahadevaiah, S.K., Turner, J.M.A., Baudat, F., Rogakou, E.P., de Boer, P., Blanco-Rodriguez, J., Jasin, M., Keeney, S., Bonner, W.M., and Burgoyne, P.S. 2001. Recombinational DNA double-strand breaks in mice precede synapsis. Nat. Genet. 27: 271-276.

Marcon, E. and Moens, P. 2003. MLH1p and MLH3p localize to precociously induced chiasmata of okadaic-acid-treated mouse spermatocytes. Genetics 165: 2283-2287.

Martinez-Perez, E., Shaw, P., Aragon-Alcaide, L., and Moore, G. 2003. Chromosomes form into seven groups in hexaploid and tetraploid wheat as a prelude to meiosis. Plant J. 36: 2129.

Meuwissen, R.L.J., Offenberg, H.H., Dietrich, A.J.J., Riesewijk, A., Vaniersel, M., and Heyting, C. 1992. A coiled-coil related protein-specific for synapsed regions of meiotic prophase chromosomes. EMBO J. 11: 5091-5100.

Meuwissen, R.L.J., Meerts, I., Hoovers, J.M.N., Leschot, N.J., and Heyting, C. 1997. Human synaptonemal complex protein 1 (SCP1): Isolation and characterization of the cDNA and chromosomal localization of the gene. Genomics 39: $377-384$.

Moore, R.C. and Purugganan, M.D. 2005. The evolutionary dynamics of plant duplicate genes. Curr. Opin. Plant Biol. 8: $122-128$.

Page, S.L. and Hawley, R.S. 2001. c(3)G encodes a Drosophila synaptonemal complex protein. Genes \& Dev. 15:31303143.

- 2004. The genetics and molecular biology of the synaptonemal complex. Annu. Rev. Cell Dev. Biol. 20: 525-558.

Pawlowski, W.P., Golubovskaya, I.N., Timofejeva, L., Meeley, R.B., Sheridan, W.F., and Cande, W.Z. 2004. Coordination of meiotic recombination, pairing, and synapsis by PHS1. Science 303: 89-92.

Rockmill, B., Sym, M., Scherthan, H., and Roeder, G.S.. 1995. Roles for 2 Reca homologs in promoting meiotic chromosome synapsis. Genes \& Dev. 9: 2684-2695.

Roeder, G.S. 1997. Meiotic chromosomes: It takes two to tango. Genes \& Dev. 11: 2600-2621.

Romanienko, P.J. and Camerini-Otero, R.D. 2000. The mouse Spoll gene is required for meiotic chromosome synapsis. Mol. Cell 6: 975-987.

Ross, K.J., Fransz, P., and Jones, G.H. 1996. A light microscopic atlas of meiosis in Arabidopsis thaliana. Chromosome Res. 4: 507-516.

Sanchez-Moran, E., Armstrong, S.J., Santos, J.L., Franklin, F.C.H., and Jones, G.H. 2002. Variation in chiasma frequency among eight accessions of Arabidopsis thaliana. Genetics 162: 1415-1422.

Sanchez-Moran, E., Jones, G.H., Franklin, F.C.H., and Santos, J.L. 2004. A puromycin-sensitive aminopeptidase is essential 
Higgins et al.

for meiosis in Arabidopsis thaliana. Plant Cell 16: 28952909.

Storlazzi, A., Xu, L.Z., Schwacha, A., and Kleckner, N. 1996. Synaptonemal complex (SC) component Zip1 plays a role in meiotic recombination independent of SC polymerization along the chromosomes. Proc. Nat1. Acad. Sci. 93: 90439048.

Suzuki, M. 1989. Spxx, a frequent sequence motif in gene regulatory proteins. J. Mol. Biol. 207: 61-84.

Sym, M., Engebrecht, J., and Roeder, G.S. 1993. Zip1 is a synaptonemal complex protein required for meiotic chromosome synapsis. Cell 72: 365-378.

Tesse, S., Storlazzi, A., Kleckner, N., Gargano, S., and Zickler, D. 2003. Localization and roles of Ski8p protein in Sordaria meiosis and delineation of three mechanistically distinct steps of meiotic homolog juxtaposition. Proc. Natl. Acad. Sci. 100: 12865-12870.

Tsubouchi, T. and Roeder, G.S. 2005. A synaptonemal complex protein promotes homology-independent centromere coupling. Science 308: 870-873.

Vazquez, J., Belmont, A.S., and Sedat, J.W. 2002. The dynamics of homologous chromosome pairing during male Drosophila meiosis. Curr. Biol. 12: 1473-1483.

von Wettstein, D., Rasmussen, S.W., and Holm, P.B. 1984. The synaptonemal complex in genetic segregation. Annu. Rev. Genet. 18: 331-413.

Wesley, S.V., Helliwell, C.A., Smith, N.A., Wang, M.B., Rouse, D.T., Liu, Q., Gooding, P.S., Singh, S.P., Abbott, D., Stoutjesdijk, P.A., et al. 2001. Construct design for efficient, effective and high-throughput gene silencing in plants. Plant $J$. 27: 581-590.

Zickler, D. and Kleckner, N. 1999. Meiotic chromosomes: Integrating structure and function. Annu. Rev. Genet. 33: 603754. 


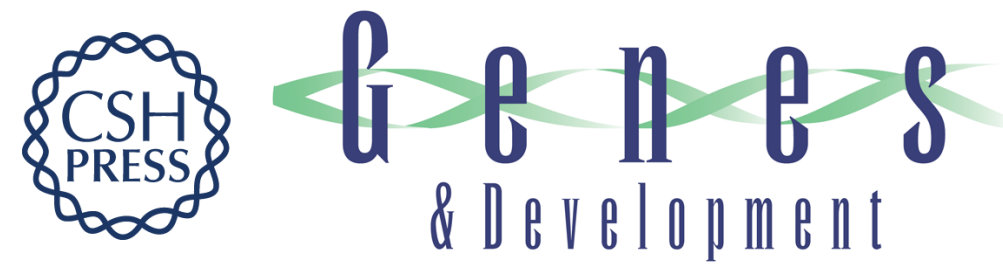

\section{The Arabidopsis synaptonemal complex protein ZYP1 is required for chromosome synapsis and normal fidelity of crossing over}

James D. Higgins, Eugenio Sanchez-Moran, Susan J. Armstrong, et al.

Genes Dev. 2005, 19:

Access the most recent version at doi:10.1101/gad.354705

Supplemental http://genesdev.cshlp.org/content/suppl/2005/09/29/19.20.2488.DC1
Material

References This article cites 43 articles, 18 of which can be accessed free at:

http://genesdev.cshlp.org/content/19/20/2488.full.html\#ref-list-1

License

Email Alerting

Receive free email alerts when new articles cite this article - sign up in the box at the top

Service

right corner of the article or click here.

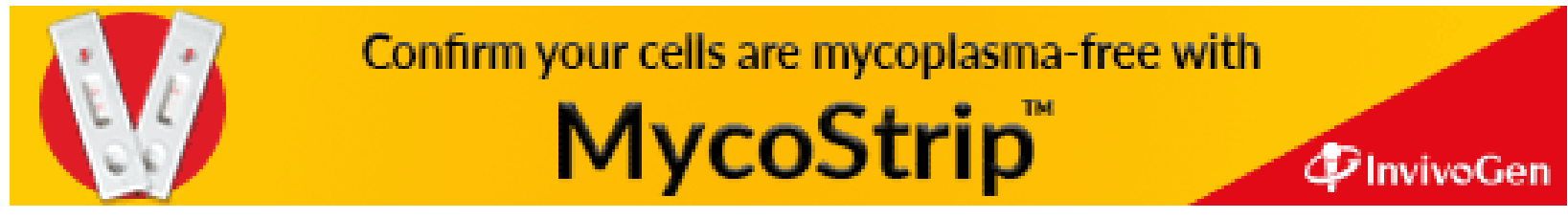

